\title{
IMPLEMENTASI METODE FORWARD CHAINING DAN CERTAINTY FACTOR DALAM MENENTUKAN BAKAT ANAK
}

\author{
Ni Kadek Ariasih ${ }^{1}$, Ladinatus Sholihah ${ }^{2}$ \\ 1,2Program Studi Teknik Informatika, STMIK STIKOM Indonesia \\ Jl. Tukad Pakerisan 97, Denpasar, Bali-Indonesia \\ Telp. (0361) 256995 Fax. (0361) 246875 \\ e-mail : kdariasih@stiki-indonesia.ac.id ${ }^{1}$, ladinatussholiha001@gmail.com²
}

\begin{abstract}
Childs has the potential for unique talents and interests from birth. Talent is the basis of intelligence, nature, and disposition that a child has from birth, while interest is a high interest in something. Children's talents and interests can be determined and changed by internal and external factors. Every parent would want their child to be successful in achieving their goals, but many parents do not know the interests and talents of their children so that there are often differences in goals between children and parents. In addition, to find out the right interests and talents, expert assistance is needed, namely psychologists and very rarely parents care about their children's interests and talents. The right solution to solve this problem is to help parents find out early information about their children's talents and interests through applications that are easily accessible to parents. In this study, an expert application was built to determine the interests and talents of children by implementing the forward chaining method and certainty factor. This method was chosen because it is able to draw results and conclusions from many different rules. The talent determination application was tested for accuracy of 8 data samples and resulted in an accuracy of $75 \%$. Based on the resulting accuracy value, it can be concluded that the talent determination application works quite well and can be used as a source of initial information for parents to find out their children's interests and talents.
\end{abstract}

Keywords - Children's Talent, Expert System, Certainty factor, Forward chaining

\begin{abstract}
ABSTRAK
Setiap anak memiliki potensi bakat dan minat yang unik semenjak dilahirkan. Bakat merupakan dasar dari kepandaian, sifat, dan pembawaan yang dimiliki seorang anak semenjak lahir, sedangkat minat merupakan ketertarikan yang tinggi terhadap sesuatu. Bakat dan minat anak dapat ditentukan dan dirubah oleh faktor internal dan eksternal. Setiap orangtua pasti menginginkan anaknya sukses menggapai cita-citanya, namun banyak orangtua yang tidak mengetahui minat dan bakat anaknya sehingga sering terjadi perbedaan tujuan antara anak dan orangtua. Selain itu, untuk mengetahui minat dan bakat yang tepat dibutuhkan bantuan pakar yaitu psikolog dan sangat jarang orangtua yang peduli terhadap pentingnya mengetahui informasi minat dan bakat anaknya. Solusi yang tepat untuk menyelesaikan masalah ini adalah membantu orangtua mengetahui informasi awal bakat dan minat anaknya melalui aplikasi yang mudah diakses orangtua. Dalam penelitian ini, dibangun sebuah aplikasi pakar untuk menentukan minat dan bakat anak dengan mengimplementasikan metode forward chaining dan certainty factor. Metode ini dipilih karena mampu mengambil hasil dan kesimpulan dari banyak aturan yang berbeda.
\end{abstract}


Aplikasi penentuan bakat dilakukan pengujian akurasi terhadap 8 sample data dan menghasilkan akurasi $75 \%$. Berdasarkan nilai akurasi yang dihasilkan dapat disimpulkan bahwa aplikasi penentuan bakat berfungsi cukup baik dan dapat dijadikan sumber informasi awal untuk orangtua mengetahui minat dan bakat anaknya.

\section{Kata Kunci- Bakat Anak, Sistem Pakar, Certainty factor, Forward chaining}

\section{Pendahuluan}

Anak merupakan makhluk spesial yang memiliki karakteristik yang unik dan berbeda-beda. Proses perkembangan anak juga tidaklah sama, sehingga dibutuhkan pemantauan tumbuh kembang anak disetiap tahapan usianya. Pemantau tumbuh kembang yang paling ideal dilakukan oleh orangtua karena orangtua paling dekat dengan anak [1].

Potensi seorang anak dapat terdiri dari minat dan bakat. Bakat dapat berupa kecerdasan, sifat, dan pembawaan yang diturunkan oleh orangtua dan bakat yang muncul karena distimulasi dengan baik. Stimulasi yang dapat dilakukan orangtua diantaranya melalui berbagai ransangan, fasilitas belajar, atau pendidikan yang dapat memicu anak untuk mengolah bakat yang dimilikinya [2].

Setiap orangtua pastilah menginginkan anaknya tumbuh dengan sehat, cerdas, dan berprestasi. Untuk mencapai hal tersebut, orangtua harus mengetahui potensi minat dan bakat yang dimiliki anaknya. Dengan mengetahui minat dan bakat akan mudah bagi orangtua untuk mengasah dan membantu anaknya mencapai cita-citanya.
Sayangnya, sangat jarang orangtua yang benar-benar peduli tentang pentingnya melihat minat dan bakat anaknya [3] sehingga sering terjadi selisih paham keinginan orangtua dan anak yang berakibat anak merasa tidak dihargai ataupun merasa gagal .

Bidang ilmu yang sangat memperhatikan perkembangan anak termasuk minat dan bakat yaitu psikologi. Jika orangtua ingin mengetahui minat dan bakat anaknya secara akurat dapat meminta pertolongan kepada psikolog. Kelebihan psikolog yaitu mampu membantu menjelaskan potensi anak berdasarkan data yang ada sehingga akan mudah orangtua memahami langkah berikutnya setelah mengetahui minat dan bakat anaknya. Namun jarang orangtua yang mendatangi psikolog untuk mengetahui minat dan bakat anaknya. Orangtua cenderung membawa anaknya ke psikolog ketika terjadi keterlambatan tumbuh kembang saja. Hal ini cukup memprihatinkan mengingat minat dan bakat sangat penting bagi seorang anak untuk mampu menggapai cita-cita yang sesuai dengan dirinya. 
Berdasarkan fakta di atas maka dalam penelitian ini solusi yang ditawarkan untuk membantu orangtua melakukan deteksi dini bakat anak adalah dengan membuat sebuah aplikasi sistem pakar penentuan bakat anak. Aplikasi ini dibangun untuk membantu orangtua untuk melakukan self-assessment terhadap anaknya. Hasil dari aplikasi ini dapat dijadikan sebagai informasi awal orangtua mengetahui minat dan bakat anak tanpa harus datang ke psikolog, terutama bagi orangtua yang terkendala akan biaya.

Aplikasi sistem pakar ini dibuat dalam bentuk website dengan mengimplementasikan metode Forward chaining dan Certainty factor untuk membantu menyimpulkan hasil dari beberapa pertanyaan yang disediakan dalam aplikasi. Metode ini dipilih karena pada aplikasi ini memerlukan banyak aturan yang berbeda untuk menghasilkan sebuah kesimpulan yang akurat. Proses penentuan bakat dilakukan dengan menghitung nilai variabel yang digunakan. Macam variable dan aturan ditentukan oleh pakar atau ahli yaitu psikolog yang dijadikan sebagai acuan dan sumber pembuatan aturan. Selain orangtua, aplikasi ini diharapkan dapat pula digunakan oleh pakar atau direkomendasikan oleh pakar untuk melakukan deteksi dini minat dan bakat anak.

\section{Metode Penelitian}

\section{1. Tahapan Penelitian}

Tahapan penelitian disusun berdasarkan metode pengembangan aplikasi dengan metode waterfall (air terjun). Model waterfall ini bersifat linier dari tahap awal hingga tahap akhir. Dimana tahapan dilakukan secara berurutan sehingga tahapan selanjutnya tidak akan bisa dilaksanakan sebelum tahapan sebelumnya selesai. Dalam metode ini, apabila terjadi kesalahan tidak bisa kembali ke tahap sebelumnya melainkan harus mengulang dari awal [4].

Adapun tahapan-tahapan dari metode pengembangan waterfall adalah : Analisis kebutuhan sistem, Perancangan Sistem, Implementasi, Pengujian, produksi dan Pemeliharaan [5]. Pada penelitian ini, tahapan-tahapan tersebut hanya akan dilakukan hingga tahap pengujian sistem saja, karena proses produksi dan pemeliharaan membutuhkan waktu lebih lama.

Secara lebih rinci, bagian-bagian apa saja yang termasuk dalam masing-masing tahapan metode waterfall dapat dilihat pada Tabel 1. 
Tabel 1. Rincian Metode Waterfall

\begin{tabular}{|l|l|}
\hline Aktivitas Inti & \multicolumn{1}{|c|}{ Penjelasan } \\
\hline $\begin{array}{l}\text { Analisis } \\
\text { kebutuhan } \\
\text { sistem }\end{array}$ & $\begin{array}{l}\text { Mengidentifikasi kebutuhan yang } \\
\text { diperlukan di dalam sistem }\end{array}$ \\
\hline & Mendefinisikan solusi \\
\hline & Menentukan kebutuhan informasi \\
\hline $\begin{array}{l}\text { Perancangan } \\
\text { sistem }\end{array}$ & $\begin{array}{l}\text { Membuat spesifikasi perancangan } \\
\text { program }\end{array}$ \\
\hline Implementasi & $\begin{array}{l}\text { Menerjemahkan pesifikasi } \\
\text { rancangan menjadi kode program }\end{array}$ \\
\hline Pengujian & Pengujian unit \\
\hline & Pengujian sistem \\
\hline $\begin{array}{l}\text { Produksi dan } \\
\text { pemeliharaan }\end{array}$ & $\begin{array}{l}\text { Mengoperasikan sistem } \\
\text { Mengevaluasi sistem }\end{array}$ \\
\hline & Memodifikasi sistem \\
\hline
\end{tabular}

\section{2. Tahapan Analisis Sistem}

Analisis kebutuhan sistem merupakan tahap pertama dalam pembangunan aplikasi dengan menggunakan metode waterfall. Tahapan ini sangat penting karena dengan analisis kebutuhan sistem yang baik mampu menghasilkan aplikasi yang sesuai dengan kebutuhan pengguna dan tepat sasaran. Tahapan analisis sistem terbagi ke dalam beberapa bagian diantaranya yaitu tahap pengumpulan data, merumuskan masalah serta solusinya, kemudian membuat kebutuhan fungsional dari sistem yang akan dibuat.

\section{2.1. Teknik Pengumpulan Data}

Data yang digunakan dalam penelitian ini adalah data primer dan data sekunder. Data primer adalah data yang dikumpulkan secara langsung dari sumbernya, yakni metode yang diperoleh dengan melakukan wawancara kepada psikolog anak. Kemudian untuk pengumpulan data sekunder diperoleh dengan menggunakan metode kepustakaan, yaitu metode yang dikumpulkan dari berbagai sumber yang dijadikan acuan atau referensi dalam penelitian ini.

\section{2.2. Kebutuhan Fungsional Sistem}

Tujuan utama dari penelitian ini adalah membuat aplikasi sistem pakar penentuan bakat anak yang dapat mengelola data bakat anak dengan bantuan psikolog sebagai sumber pembuat aturan. Selain itu, aplikasi ini ditujukan agar orang tua mampu melakukan self-assessment untuk mengetahui bakat anak dan mencetak hasil konsultasi sebagai bahan deteksi dini bakat anak.

\section{2.3. Metode Sistem Pakar}

\section{a. Forward chaining}

Metode yang sering digunakan dalam sistem pakar yaitu metode forward chaining. Penarikan kesimpulan dalam metode ini dilakukan dengan menginputkan fakta yang ada kemudian mencocokan dengan fakta yang tersimpan dalam rules dengan menggunakan fungsi IF dan IF-Then [6].

Metode forward chaining merupakan metode penalaran maju yang diartikan fakta yang diinputkan oleh user akan dievaluasi dengan mencocokan satu-satu 
dengan urutan tertentu terhadap aturanaturan yang ada pada mesin inferensi. Selanjutnya akan disimpulkan hasilnya dengan memberikan predikat salah dan benar. Setelah memperoleh nilai benar, akan disimpan dan dilanjutkan ke aturan selanjutnya hingga semua fakta selesai dicocokan dengan aturan yang ada. Proses pencocokan fakta dan aturan ini dilakukan berulang hingga didapatkan suatu kesimpulan akhir [7].

Kelebihan dari metode forward chaining adalah mampu bekerja dengan baik dimulai dari mengumpulkan fakta yang kemudian diambil kesimpulan dari data dalam jumlah kecil maupun besar. Sedangkan kelemahan metode ini adalah memungkinkan terjadi kebingungan dalam menentukan fakta yang utama diantara fakta yang lainnya karena tidak adanya cara untuk mengenali informasi yang utama.

\section{b. Certainty factor}

Metode yang mendefinisikan tingkat kepastian terhadap fakta atau aturan yang menggambarkan keyakinan seorang pakar terhadap masalah yang dihadapi disebut metode Certainty factor. Metode ini didefinisikan pula sebagai metode yang digunakan untuk membuktikan sebuah fakta itu pasti atau tidak pasti. Certainty factor digunakan untuk mengambil kesimpulan dari sesuatu yang belum pasti, Pada faktor kepastian ini terdapat suatu nilai yang disebut Certainty factor (CF) yang digunakan untuk mengekspresikan derajat keyakinan.[8].

Certainty factor didefinisikan dalam persamaan berikut ini.

$$
\mathrm{CF}[\mathrm{H} . \mathrm{E}]=\mathrm{MB}[\mathrm{H}, \mathrm{E}]-\mathrm{MD}[\mathrm{H}, \mathrm{E}]
$$

Dimana CF merupakan certainty factor (faktor kepastian) dalam hipotesis $\mathrm{H}$ yang dipengaruhi oleh gejala $\mathrm{E}$ yang didapatkan dari mengurangi $\mathrm{MB} \quad[\mathrm{H}, \mathrm{E}]$ yang merupakan ukuran kenaikan kepercayaan (measure of increased belief) terhadap hipotesis $\mathrm{H}$ yang dipengaruhi gejala $\mathrm{E}$ dengan MD $\mathrm{L}[\mathrm{H}, \mathrm{E}]$ yang merupakan ukuran kenaikan ketidakpercayaan (measure of increased disbelief) terhadap hipotesis $\mathrm{H}$ yang dipengaruhi gejala $\mathrm{E}$.

Besarnya nilai $\mathrm{CF}$ berkisar antara -1 sampai 1. Nilai -1 digunakan untuk menyatakan ketidapercayaan mutlak sedangkan nilai 1 menunjukkan kepercayaan mutlak.

Kelebihan metode $\mathrm{CF}$ adalah cocok dipakai dalam sistem pakar untuk mengukur kepastian diagnosis. Hal ini didasari kemampuan hitung metode ini hanya dapat mengolah 2 data saja sehingga keakuratan data dapat terjaga [9]. Dibalik keakuratan data yang dapat terjaga metode ini memiliki kelemahan yaitu 
perlu dilakukan pengolahan data beberapa kali untuk data lebih dari dua.

\section{2.4. Perhitungan Akurasi}

Pengujian akurasi dilakukan untuk mengetahui tingkat akurasi aplikasi yang telah dibangun. Pengujian akurasi dilakukan dengan ujicoba diagnosa berdasarkan standar US Office Of Education (USEO) America untuk mengetahui keakuratan sistem ini diawali dengan cara membandingkan hasil prediksi dari sistem dengan hasil prediksi dari seorang pakar. Kemudian dilanjutkan menghitung akurasi dengan menggunakan rumus akurasi data berikut [10] :

$$
\text { Akurasi }=\frac{\text { jumlah data ahurat }}{\text { jumlah seluruh data }} \times 100 \%
$$

Nilai akurasi didapatkan dari membagi jumlah data akurat yang dikeluarkan oleh pakar dengan jumlah seluruh data dikalikan serratus persen untuk hasil dalam bentuk presentase.

\section{3. Perancangan Sistem}

Perancangan sistem menjadi bagian yang penting dalam metode waterfall. Perancangan sistem bertujuan untuk memberikan gambaran gambaran atau desain sistem yang akan dibangun sehingga dapat diimplementasikan dan sesuai dengan kebutuhan pengguna sistem [11]. Perancangan aplikasi penentuan bakat anak ini akan ditampilkan dalam model UML menggunakan use case diagram dan class diagram.

\section{3.1. Use Case Diagram}

Use case diagram merupakan model yang akan menggambarkan fungsionalitas yang disediakan dalam sistem dan dan siapa saja yang dapat menggunakan fungsi tersebut. Use case diagram diartikan pula sebagai pemodelan untuk kelakuan dari sistem yang akan dibangun [12]. Pada Gambar 1 merupakan use case diagram dari sistem pakar penentuan bakat anak yang terdiri dari dua user yaitu pakar dan orangtua.

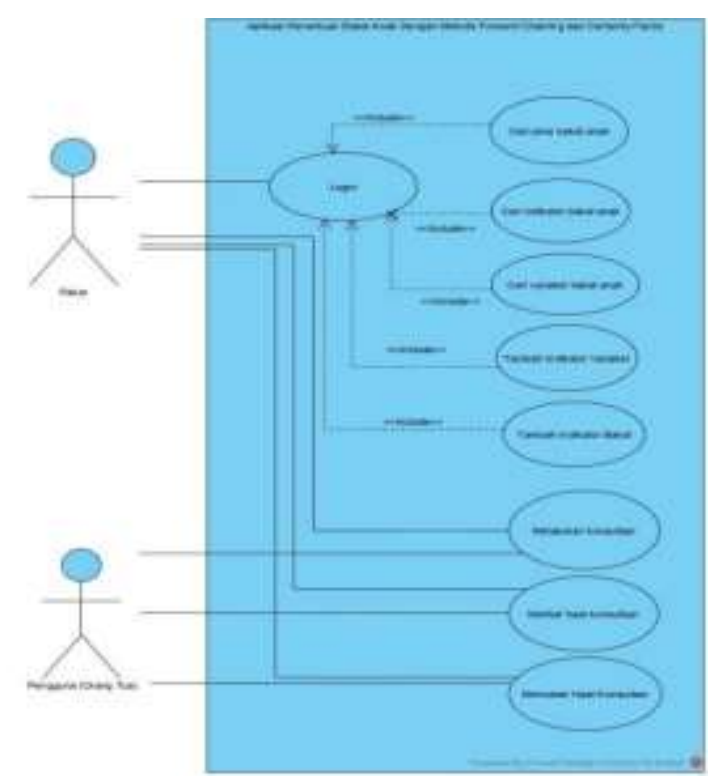

Gambar 1. Use Case Diagram

\section{3.2. Class Diagram}

Class diagram merupakan pemodelan yang digunakan untuk menggambarkan dan mendefinisikan kelas objek yang terbentuk oleh entity. Fungsi dari 
pemodelan class diagram adalah untuk mendefinisikan struktur sistem yang terdiri dari kelas-kelas yang akan dibangun dalam sebuah sistem [13]. Berawal dari class diagram akan terbentuk sekumpulan table yang akan saling berhubungan membentuk database. Pada Gambar 2 merupakan class diagram untuk sistem pakar pada penelitian ini

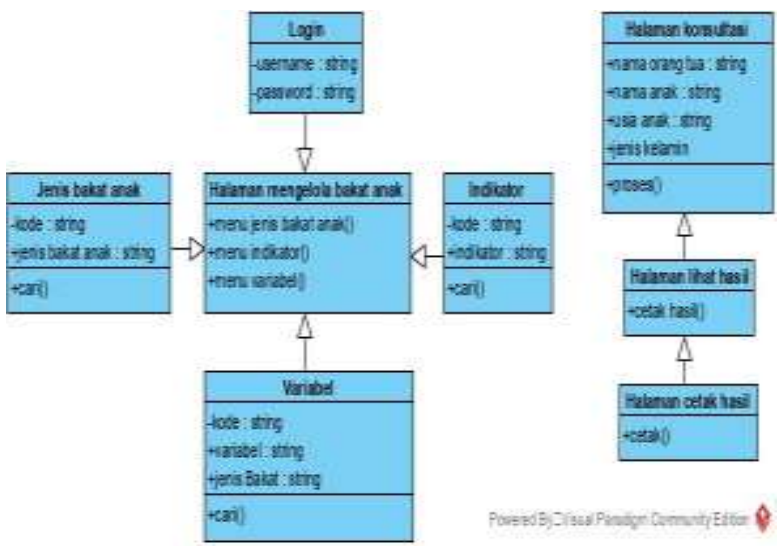

Gambar 2. Class Diagram

\section{Hasil dan Pembahasan}

\subsection{Implementasi Metode Sistem Pakar}

Data bakat anak yang akan diimplementasikan dalam penelitian ini menggunakan data standar US Office of Education (USEO) dengan 6 jenis bakat anak, 27 indikator, 83 variabel dan 33 aturan untuk dijadikan sebagai knowledge base dalam sistem pakar ini. Pada Tabel 2 merupakan 6 jenis bakat anak, Tabel 3 menunjukkan indicator bakat anak, dan Tabel 4 merupakan aturan.

\section{Tabel 2. Jenis Bakat Anak}

\begin{tabular}{|c|c|}
\hline Kode & Kriteria Bakat Anak \\
\hline $\mathrm{K} 1$ & Intelektual Umum \\
\hline
\end{tabular}

\begin{tabular}{|c|c|}
\hline K2 & Akademik \\
\hline K3 & Pola Pikir Kreatif dan Produktif \\
\hline K4 & Leadership \\
\hline K5 & Kemampuan Seni \\
\hline K6 & Psikomotorik \\
\hline
\end{tabular}

Tabel 3. Indicator Bakat Anak

\begin{tabular}{|l|l|}
\hline Kode & \multicolumn{1}{|c|}{ Keterangan } \\
\hline I1 & Pembendaharaan kosa kata yang tinggi \\
\hline I2 & Ingatan yang kuat \\
\hline I3 & Penguasaan kata-kata abstrak \\
\hline I4 & Memiliki pemikiran abstrak \\
\hline I5 & Memiliki prestasi bidang matematika \\
\hline I6 & Memiliki prestasi sains \\
\hline I7 & Keterbukaan terhadap pengalaman \\
\hline I8 & Menetapkan standar personal \\
\hline I9 & Kemampuan memainkan ide-ide \\
\hline I10 & Keinginan untuk menghadapi resiko \\
\hline I11 & Kesukaan terhadap kompleksitas \\
\hline I12 & Toleran terhadap ambiguitas \\
\hline I13 & Image diri yang positif \\
\hline I14 & Kemampuan menyatu dengan tugas \\
\hline I15 & Kepercayaan diri \\
\hline I16 & Tanggung Jawab \\
\hline I17 & Kerja sama \\
\hline I18 & Kecenderungan untuk mendominasi \\
\hline & $\begin{array}{l}\text { Beradaptasi dengan mudah terhadap } \\
\text { situasi yang baru }\end{array}$ \\
\hline I19 & Keterbakatan dalam bidang seni visual \\
\hline I20 & Keterbakatan dalam bidang seni musik \\
\hline I21 & Keterbakatan dalam bidang drama \\
\hline I22 & Kemampuan motorik kinestetik \\
\hline I23 & Keterampilan praktik \\
\hline I24 & Keterampilan spasial \\
\hline I25 & Keterampilan mekanika \\
\hline I26 & Keterampilan fisikal \\
\hline I27 & Kamanamatam \\
\hline
\end{tabular}

Namun terdapat beberapa aturan tambahan berdasarkan pemetaan kembali variabel-variabel sesuai jenisnya oleh ibu Aritya Widianti, S.Psi., M.Psi., Psikolog, selaku pakar dalam sistem ini. Kemudian aturan akan terus bertambah seiring dengan berkembangnya sistem, karena dengan menggunakan metode forward chaining membutuhkan kombinasi aturan yang lebih banyak agar dalam beberapa kasus sistem mampu menampilkan hasil dan kesimpulan yang akurat. Pada Tabel 5 
merupakan aturan tambahan yang diberikan dalam implementasi aplikasi penentuan bakat ini.

\section{Tabel 4. Aturan}

\begin{tabular}{|l|l|}
\hline Kode & \multicolumn{1}{|c|}{ Keterangan } \\
\hline 1 & if C1 \& C2 \& C3 then I1 \\
\hline 2 & $\begin{array}{l}\text { if C4 \& C5 \& C6 \& C7 \& C8 \& C9 then } \\
\text { I }\end{array}$ \\
\hline 3 & $\begin{array}{l}\text { if C10 \& C11 \& C12 \& C13 \& C14 then } \\
\text { I3 }\end{array}$ \\
\hline 4 & if I1 \& I2 \& I3 then K1 \\
\hline 5 & if C15 \& C16 \& C17 \& C18 then I4 \\
\hline 6 & $\begin{array}{l}\text { if C19 \& C20 \& C21 \& C22 \& C23 \& } \\
\text { C24 \& C25 then I5 }\end{array}$ \\
\hline 7 & if I4 \& I5 then K2 \\
\hline 8 & if C26 \& C27 then I6 \\
\hline 9 & $\begin{array}{l}\text { if C28 \& C29 \& C30 \& C31 \& C32 then } \\
\text { I7 }\end{array}$ \\
\hline 10 & if C33 \& C34 then I8 \\
\hline 11 & if C35 \& C36 then I9 \\
\hline 12 & if C37 \& C38 \& C39 \& C40 then I10 \\
\hline 13 & if C41 \& C42 \& C43 then I11 \\
\hline 14 & if C44 \& C45 \& C46 then I12 \\
\hline 15 & if C47 \& C48 then I13 \\
\hline 16 & $\begin{array}{l}\text { if I6 \& I7 \& I8 \& I9 \& I10 \& I11 \& I12 \& } \\
\text { I13 then K3 }\end{array}$ \\
\hline 17 & if C49 \& C50 then I14 \\
\hline 18 & if C51 \& C52 then I15 \\
\hline 19 & $\begin{array}{l}\text { if C53 \& C54 \& C55 \& C56 \& C57 then } \\
\text { I16 }\end{array}$ \\
\hline 20 & if C58 \& C59 then I17 \\
\hline 21 & if C60 \& C61 \& C62 then I18 \\
\hline 22 & if I14 \& I15 \& I16 \& I17 \& I18 then K4 \\
\hline 23 & if C63 \& C64 then I19 \\
\hline 24 & if C65 \& C66 then I20 \\
\hline 25 & if C67 \& C68 then I21 \\
\hline 26 & if C69 then I22 \\
\hline 27 & if I19 \& I20 \& I21 \& I22 then K5 \\
\hline 28 & if C70 \& C71 \& C72 then I23 \\
\hline 29 & if C73 \& C74 then I24 \\
\hline 30 & if C75 \& C76 \& C77 then I25 \\
\hline 31 & if C78 \& C79 \& C80 \& C81 then I26 \\
\hline 32 & if C82 \& C83 then I27 \\
\hline 33 & if I23 \& I24 \& I25 \& I26 \& I27 then K6 \\
\hline
\end{tabular}

Tabel 5. Aturan Tambahan

\begin{tabular}{|l|l|}
\hline No & \multicolumn{1}{|c|}{ Aturan } \\
\hline 34 & $\begin{array}{l}\text { If C15 \& C16 \& C17 \& C18 \& C27 \& C46 } \\
\text { \& C52 then I2 }\end{array}$ \\
\hline 35 & If C26 \& C32 \& C33 \& C35 then I1 \\
\hline 36 & If I1 \& I2 then K1 \\
\hline 37 & $\begin{array}{l}\text { If C1 \& C7 \& C9 \& C10 \& C12 \& C13 } \\
\text { then I4 }\end{array}$ \\
\hline 38 & If I4 then K2 \\
\hline 39 & If C1 \& C7 \& C10 then I11 \\
\hline 40 & If C11 \& C12 then I9 \\
\hline 41 & If C13 \& C14 then I7 \\
\hline
\end{tabular}

\begin{tabular}{|c|c|}
\hline 42 & If I7 \& I9 \& I11 then K3 \\
\hline 43 & If $\mathrm{C} 1 \& \mathrm{C} 10 \& \mathrm{C} 12 \& \mathrm{C} 13$ then $\mathrm{I} 14$ \\
\hline 44 & If $\mathrm{C} 2 \& \mathrm{C} 3 \& \mathrm{C} 14 \& \mathrm{C} 26 \&$ C27 then I15 \\
\hline 45 & If C35 \& C36 \& C48 then I16 \\
\hline 46 & If I14 \& I15 \& I16 then K4 \\
\hline 47 & If $\mathrm{C} 1 \& \mathrm{C} 10$ then 122 \\
\hline 48 & If $\mathrm{C} 4 \& \mathrm{C} 7$ then 121 \\
\hline 49 & $\begin{array}{l}\text { If C6 \& C11 \& C19 \& C20 \& C21 \& C34 } \\
\text { \& C47 then } 120\end{array}$ \\
\hline 50 & If $\mathrm{C} 22$ \& $\mathrm{C} 23$ \& $\mathrm{C} 24 \& \mathrm{C} 25$ then 119 \\
\hline 51 & If I19 \& I20 \& I $21 \&$ I 22 then K5 \\
\hline 52 & $\begin{array}{l}\text { If } \mathrm{C} 1 \text { \& } \mathrm{C} 37 \text { \& } \mathrm{C} 40 \text { \& } \mathrm{C} 48 \text { \& } \mathrm{C} 67 \text { \& } 68 \\
\text { \& } \mathrm{C} 69 \text { then I24 }\end{array}$ \\
\hline 53 & If I24 then K6 \\
\hline 54 & $\begin{array}{l}\text { if } \mathrm{C} 1 \& \mathrm{C} 2 \& \mathrm{C} 3 \& \mathrm{C} 26 \& \mathrm{C} 32 \& \mathrm{C} 33 \& \\
\mathrm{C} 35 \text { then I1 }\end{array}$ \\
\hline 55 & $\begin{array}{l}\text { if C4 \& C5 \& C6 \& C7 \& C8 \& C9 \& C15 } \\
\text { \& C16 \& C17 \& C18 \& C27 \& C46 \& C52 } \\
\text { then I2 }\end{array}$ \\
\hline 56 & If $\mathrm{C} 10$ \& $\mathrm{C} 11 \& \mathrm{C} 12 \& \mathrm{C} 13 \& \mathrm{C} 14$ then $\mathrm{I} 3$ \\
\hline 57 & If I1 \& I $2 \&$ I 3 then $\mathrm{K} 1$ \\
\hline 58 & $\begin{array}{l}\text { If } \mathrm{C} 1 \text { \& } \mathrm{C} 7 \text { \& } \mathrm{C} 9 \text { \& } \mathrm{C} 10 \text { \& } \mathrm{C} 12 \text { \& } \mathrm{C} 13 \text { \& } \\
\mathrm{C} 15 \text { \& } 16 \text { \& } 17 \text { \& } \mathrm{C} 18 \text { then I4 }\end{array}$ \\
\hline 59 & $\begin{array}{l}\text { if C19 \& C20 \& C21 \& C22 \& C23 \& C24 } \\
\text { \& C25 then I5 }\end{array}$ \\
\hline 60 & if I4 \& I5 then $\mathrm{K} 2$ \\
\hline 61 & if $\mathrm{C} 26$ \& $\mathrm{C} 27$ then I6 \\
\hline 62 & $\begin{array}{l}\text { if } \mathrm{C} 13 \text { \& } \mathrm{C} 14 \text { \& } \mathrm{C} 28 \text { \& } \mathrm{C} 29 \& \mathrm{C} 30 \text { \& } \mathrm{C} 31 \\
\text { \& C32 then I7 }\end{array}$ \\
\hline 63 & if $\mathrm{C} 33$ \& C34 then I8 \\
\hline 64 & if $\mathrm{C} 11 \& \mathrm{C} 12 \& \mathrm{C} 35 \& \mathrm{C} 36$ then 9 \\
\hline 65 & if $\mathrm{C} 37$ \& $\mathrm{C} 38$ \& $\mathrm{C} 39 \& \mathrm{C} 40$ then $\mathrm{I} 10$ \\
\hline 66 & $\begin{array}{l}\text { if C1 \& C7 \& C10 \& C41 \& C42 \& C43 } \\
\text { then I1 }\end{array}$ \\
\hline 67 & if C44 \& C45 \& C46 then I12 \\
\hline 68 & if $\mathrm{C} 47$ \& $\mathrm{C} 48$ then $\mathrm{I} 13$ \\
\hline 69 & $\begin{array}{l}\text { if I6 \& I7 \& I8 \& I9 \& I10 \& I1 } 1 \& \text { I12 \& } \\
\text { I13 then K3 }\end{array}$ \\
\hline 70 & $\begin{array}{l}\text { if C1 \& C10 \& C12 \& C13 \& C49 \& C50 } \\
\text { then I14 }\end{array}$ \\
\hline 71 & $\begin{array}{l}\text { if } \mathrm{C} 2 \& \text { C3 \& C14 \& C26 \& C27 \& C51 \& } \\
\text { C52 then I15 }\end{array}$ \\
\hline 72 & $\begin{array}{l}\text { if C35 \& C36 \& C48 \& C53 \& C54 \& C55 } \\
\text { \& C56 \& C57 then I16 }\end{array}$ \\
\hline 73 & if C58 \& C59 then I17 \\
\hline 74 & if C60 \& C61 \& C62 then I18 \\
\hline 75 & if I14 \& I15 \& I16 \& I17 \& I18 then K4 \\
\hline 76 & $\begin{array}{l}\text { if C22 \& C23 \& C24 \& C25 \& C63 \& C64 } \\
\text { then I19 }\end{array}$ \\
\hline 77 & $\begin{array}{l}\text { if C6 \& C11 \& C19 \& C20 \& C21 \& C34 } \\
\text { \& C47 \& C65 \& C66 then I20 }\end{array}$ \\
\hline 78 & if $\mathrm{C} 4 \& \mathrm{C} 7 \& \mathrm{C} 67$ \& $\mathrm{C} 68$ then $\mathrm{I} 21$ \\
\hline 79 & if $\mathrm{C} 1 \& \mathrm{C} 10$ \& $\mathrm{C} 69$ then $\mathrm{I} 22$ \\
\hline 80 & if I19 \& I 20 \& I $21 \& \mathrm{I} 22$ then $\mathrm{K} 5$ \\
\hline 81 & if C70 \& C71 \& C72 then I23 \\
\hline 82 & $\begin{array}{l}\text { if C1 \& C37 \& C40 \& C48 \& C67 \& C68 } \\
\text { \& C69 \& C73 \& C74 then I24 }\end{array}$ \\
\hline 83 & if C75 then I25 \\
\hline 84 & if I $23 \& \mathrm{I} 24 \& \mathrm{I}$ \\
\hline
\end{tabular}




\subsection{Implementasi Aplikasi}

Aplikasi penentuan bakat anak dibangun dalam bentuk website menggunakan bahasa pemrograman PHP, HTML, dan menggunakan framework Codeigniter. Aplikasi ini terdiri dari dua menu utama yang disediakan untuk pakar dan orangtua.

Di dalam menu pakar terdapat sub menu yaitu halaman data bakat, data indicator, dan data variable yang ditampilkan pada Gambar 3. Sedangkan menu orangtua terdiri dari halaman konsultasi seperti pada Gambar 4, hasil konsultasi seperti pada Gambar 5, dan cetak hasil konsultasi.

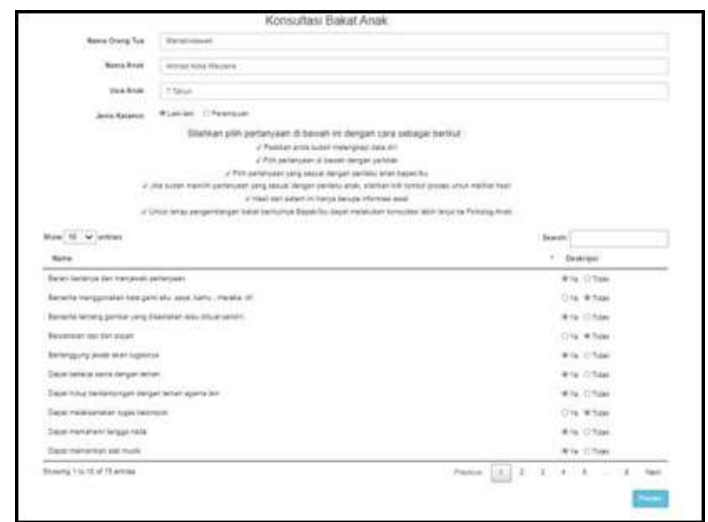

Gambar 3. Tampilan Halaman Data Bakat Untuk Pakar

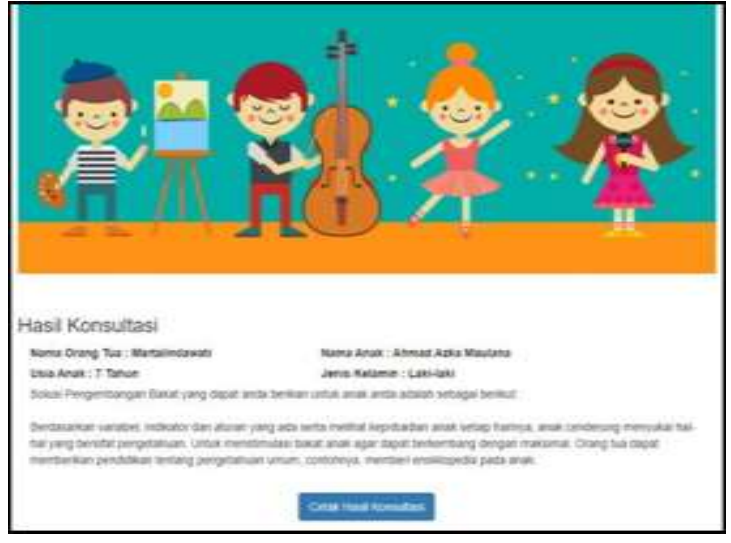

Gambar 4. Tampilan Halaman Konsultasi Untuk Orang Tua

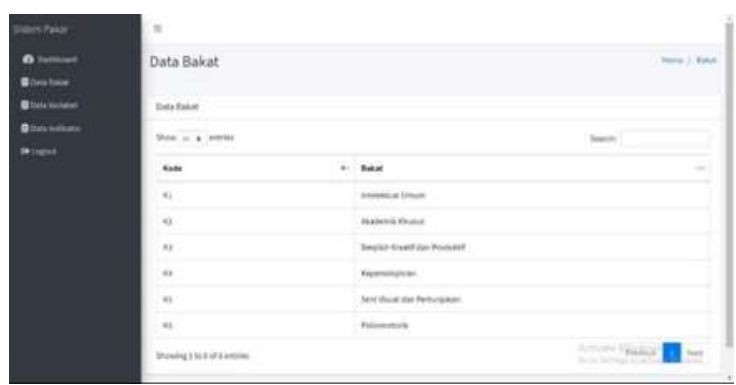

Gambar 5. Tampilan Halaman Hasil Konsultasi Untuk Orang Tua

\subsection{Pengujian Akurasi}

Pengujian akurasi dilakukan dengan membandingkan hasil analisis dari pakar dengan hasisl analisis yang dihasilkan oleh aplikasi. Pengujian ini dilakukan dengan objek uji 8 sampel data dan didapatkan hasil seperti pada Tabel 6. Dalam tabel 6 akurasi bernilai 1 jika hasil analisis pakar sama dengan hasil analisis aplikasi dan begitu sebaliknya hasil analisis bernilai 0 jika hasil analisis pakar tidak sama dengan hasil analisis aplikasi. 
Tabel 6. Hasil Pengujian Akurasi

\begin{tabular}{|c|c|c|c|c|}
\hline $\begin{array}{l}\mathbf{N} \\
\mathbf{0}\end{array}$ & $\begin{array}{l}\text { Nama } \\
\text { Pasien }\end{array}$ & $\begin{array}{c}\text { Hasil } \\
\text { Analisis } \\
\text { Pakar }\end{array}$ & $\begin{array}{c}\text { Hasil } \\
\text { Analisis } \\
\text { Aplikasi }\end{array}$ & $\begin{array}{c}\text { Akura } \\
\text { si }\end{array}$ \\
\hline 1 & $\begin{array}{c}\text { Ahmad } \\
\text { Azka } \\
\text { Maulana }\end{array}$ & $\begin{array}{c}\text { Kepemimpi } \\
\text { nan }\end{array}$ & $\begin{array}{c}\text { Kepemimpi } \\
\text { nan }\end{array}$ & 1 \\
\hline 2 & $\begin{array}{l}\text { Najwa } \\
\text { Syafira } \\
\text { Azzahra }\end{array}$ & $\begin{array}{c}\text { Intelektual } \\
\text { Umum }\end{array}$ & $\begin{array}{l}\text { Intelektual } \\
\text { Umum }\end{array}$ & 1 \\
\hline 3 & $\begin{array}{c}\text { \&ara } \\
\text { Adreena } \\
\text { Anindita }\end{array}$ & $\begin{array}{c}\text { Kepemimpi } \\
\text { nan }\end{array}$ & $\begin{array}{c}\text { Kepemimpi } \\
\text { nan }\end{array}$ & 1 \\
\hline 4 & $\begin{array}{c}\text { Maulana } \\
\text { Abdul } \\
\text { Ghani }\end{array}$ & $\begin{array}{l}\text { Intelektual } \\
\text { Umum }\end{array}$ & $\begin{array}{c}\text { Seni Visual } \\
\text { dan } \\
\text { Pertunjukka } \\
\text { n }\end{array}$ & 0 \\
\hline 5 & $\begin{array}{c}\text { Farhana } \\
\text { Shakayla } \\
\text { Sheza }\end{array}$ & $\underset{\text { nan }}{\text { Kepemimpi }}$ & $\begin{array}{c}\text { Kepemimpi } \\
\text { nan }\end{array}$ & 1 \\
\hline 6 & $\begin{array}{c}\text { Gendis } \\
\text { Laila } \\
\text { Mahmud } \\
\text { ah }\end{array}$ & $\begin{array}{c}\text { Kepemimpi } \\
\text { nan }\end{array}$ & $\begin{array}{c}\text { Kepemimpi } \\
\text { nan }\end{array}$ & 1 \\
\hline 7 & $\begin{array}{c}\text { Aqila } \\
\text { Shaquee } \\
\text { na } \\
\text { Salsabila }\end{array}$ & $\begin{array}{c}\text { Kepemimpi } \\
\text { nan }\end{array}$ & $\begin{array}{c}\text { Kepemimpi } \\
\text { nan }\end{array}$ & 1 \\
\hline 8 & $\begin{array}{l}\text { M Afif } \\
\text { Sulthon } \\
\text { Auliya }\end{array}$ & $\begin{array}{l}\text { Intelektual } \\
\text { Umum }\end{array}$ & $\begin{array}{c}\text { Tidak } \\
\text { Menampilka } \\
\text { n Hasil }\end{array}$ & 0 \\
\hline
\end{tabular}

Berdasarkan hasil pengujian akurasi pada tabel 5, dapat dilakukan perhitungan persentase akurasi dengan hasil sebagai berikut.

Nilai Akurasi $=\frac{\text { Kecocokandata }}{\text { Total data }} \times 100 \%$

Nilai Akurasi $=\frac{6}{8} \times 100 \%$

Nilai Akurasi $=75 \%$

Dari data yang telah diuji didapatkan nilai akurasi $75 \%$ karena 6 data menunjukkan sesuai dari 8 data yang diuji. Nilai akurasi akan meningkat jika data uji yang diberikan ditambah.

\section{Simpulan}

Berdasarkan penelitian yang telah dilakukan dapat disimpulkan bahwa metode forward chaining dan certainty factor dapat diimplementasikan dengan baik pada aplikasi sistem pakar penentuan bakat anak. Dilihat dari hasil pengujian akurasi dengan menggunakan 8 sample data memperoleh nilai akurasi sebesar $75 \%$. Nilai akurasi tersebut menunjukkan hasil analisis sistem pakar berfungsi cukup baik sesuai dengan hasil analisis pakar. Namun nilai akurasi ini bisa bertambah apabila data uji dalam jumlah banyak. Selain itu secara fungsionalitas, aplikasi ini sudah mampu memenuhi kebutuhan pakar dan orang tua untuk membantu melakukan deteksi dini bakat anak.

\section{DAFTAR PUSTAKA}

[1] H. Permono, "Peran Orang Tua dalam Optimalisasi Tumbuh Kembang Anak untuk Membangun Karakter Anak Usia Dini," in Prosiding Seminar Nasional Parenting, 2013, pp. 34-47.

[2] I. A. Anggraini, W. D. Utami, and S. B. Rahma, "Mengidentifikasi Minat Bakat Siswa Sejak Usia Dini di SD Adiwiyata," Islam. J. Keislam. dan Ilmu Pendidik., vol. 2, no. 1, pp. 161-169, 2020, doi: 10.36088/islamika.v2i1.570. 
[3] A. Holis, "Peranan Keluarga/Orang Tua dan Sekolah dalam Mengembangkan Kreativitas Anak Usia Dini," J. Pendidik. Univ. Garut, vol. 1, no. 1, pp. 22-43, 2007.

[4] G. Wiro Sasmito, "Penerapan metode Waterfall pada desain sistem informasi geografis industri kabupaten Tegal," J. Inform. Pengemb. IT, vol. 2, no. 1, pp. 6$12,2017$.

[5] D. Zaliluddin and R. Rohmat, "Perancangan Sistem Informasi Penjualan Berbasis Web (Studi Kasus Pada Newbiestore)," Infotech J., vol. 4, no. 1, p. 236615, 2018.

[6] D. Kusbianto, R. Ardiansyah, and D. A. Hamadi, "Implementasi Sistem Pakar Forward chaining Untuk Identifikasi Dan Tindakan Perawatan Jerawat Wajah," Polinema, J. Inform., vol. 4, no. 1, pp. 71-80, 2017.

[7] E. D. S. Mulyani and I. N. Restianie, “Aplikasi Sistem Pakar Untuk Mendiagnosa Penyakit Anak (Balita) Dengan Menggunakan metode Forward chaining," in Seminar Nasional Teknologi Informasi dan Multimedia 2016, 2016, pp. 43-48.

[8] R. Rachman and A. Mukminin,
"Penerapan Metode Certainty factor Pada Sistem Pakar Penentuan Minat dan Bakat Siswa SD," Khazanah Inform. J. Ilmu Komput. dan Inform., vol. 4, no. 2, p. 90, 2018, doi: 10.23917/khif.v4i2.6828.

[9] N. A. Putri, "Sistem Pakar Untuk Mengidentifikasi Kepribadian Siswa Menggunakan Metode Certainty factor Dalam Mendukung Pendekatan Guru," J. Inf. Technol. Comput. Sci., vol. 1, no. 1, pp. 7890, 2018.

[10] E. H. Wijaya and N. Hidayat, "Diagnosis Penyakit Cabai dengan Menggunakan Metode Forward chaining - Dempster-Shafer," $J$. Pengemb. Teknol. Inf. Dan Ilmu Komput., vol. 2, no. 12, pp. $7202-$ 7208, 2018.

[11] J. T. Informasi, W. Rahayu, P. S. Informatika, and S. Informasi, "Rancang Bangun Sistem Informasi Akademik Pada SMK Citra Dharma Berbasis JAVA," vol. 5, no. 2, 2019.

[12] Munawar, Analisis Perancangan sistem berorientasi objek dengan UML. Bandung, 2018.

[13] S. Julianto and S. Setiawan, "Perancangan Sistem Informasi Pemesanan Tiket Bus Pada Po. Handoyo Berbasis Online," 
Simatupang, Julianto Sianturi,

Setiawan, vol. 3, no. 2, pp. 11-25, 2019.

[14] Wibowo, H., \& Indriyani, F. (2018,

October). K-Nearest Neighbor

Method For Monitoring Of

Production And Preservation

Information (Treatment) Of Rubber

Tree Plant. In International

Conference on Information

Technology and Business

(ICITB) (pp. 29-44).

[15] Setiawan, M. (2017, October).

Metode K-Means Untuk Sistem

Informasi Pengelompokan

Mahasiswa Baru Pada Perguruan

Tinggi. In Prosiding Seminar

Nasional Darmajaya (Vol. 1, No. 1, pp. 130-145).

[16] Fitria, S. Y., \& SeptiliaArfida, H. Green Cloud Computing Ideas with Security Issues in Setting of Distributed Computing and Cloud Framework. 